\title{
Acute Poisoning Induced Coma: Characteristics and Predictive Role of Early Creatine Phosphokinase on Its Outcome
}

\author{
Eman Abdelfath Mohammed ${ }^{1}$ and EL -Sayed Hamdey EL-Sayed Gawesh ${ }^{2}$ \\ ${ }^{1}$ Department of Forensic Medicine and Clinical Toxicology, Faculty of Medicine, Ain Shams University. \\ 2 Department of Forensic Medicine and Clinical Toxicology, Faculty of Medicine, Al- Azhar University. \\ Cairo, Egypt.
}

\begin{abstract}
Background: Emergency physicians are often challenged with a comatose patient; 30\% of patients with coma of unknown origin are due to intoxication. Comatose patients are at high risk for morbidity and mortality. Objective: The present study assessed poisoning-induced coma regarding demographic and intoxication data, causative agents, clinical data, management modalities and outcome. In addition to evaluation of the role of creatine phosphokinase (CPK) level on admission and other variables as predictive factors for the outcome in toxic coma. Subjects and Methods: This study was conducted prospectively on one hundred comatose intoxicated patients, admitted to Poison Control Center Ain Shams University Hospitals (PCCASU). Results: The majority of patients (64\%) were in the age group 18-40 year, and there was male predominance (56\%). Organophosphorus, carbamazepine and tramadol were the most common toxic agents inducing coma. Death rate was $12 \%$ and mortality is much higher in patients with older age, elevated admission creatine phosphokinase, longer duration of hospital stay and higher grade of Reed's classification of coma. Conclusion: Organophosphorus followed by carbamazepine and tramadol were the most common toxic agents inducing coma. Older age, elevated admission creatine phosphokinase, longer duration of hospitalization and higher grade of Reed's classification of coma can predict the mortality. In addition, respiratory acidosis and the need of intubation and mechanical ventilation indicated poorer outcome, while administration of antidotes was correlated with better outcome.
\end{abstract}

Key words Poisoning induced coma, creatine phosphokinase, predictive factors, mortality, Poison Control Center.

\section{Introduction}

I mpaired consciousness represents a diagnostic problem in the emergency department. However, studies on its characteristics are limited. Poisoning has been shown to be the most common underlying cause (Forsberg et al., 2009). Comatose patients are at high risk for morbidity and mortality, a rapid and systematic diagnostic work up to evaluate and potentially treat the underlying etiology is mandatory (David and Greer, 2013).

Toxic agents may produce coma through a direct effect on brain cells or as a result of derangements secondary to agents, which may also indirectly harm the function of the ascending reticular activating system and lead to coma (Young, 2009).

The outcome of coma is related to the cause independent of the physical signs, depth or length of coma (Bates, 2001). However, duration of coma appears to be predictive of recovery. Patients in vegetative state or who remain comatose for 1 month following the acute event have little or no chance of recovery, and many of these patients will die (Heyerdahl et al., 2008). Glasgow Coma Scale (GCS) has been used for recovery evaluation of patients admitted to ICU following drug overdose, the need for intubation in patients and for predicting acute and delayed poisoning outcome (Eizadi-Mood et al., 2011).

Biochemical studies, such as creatine phosphokinase and neuron specific enolase, have been correlated with outcome (Bates, 2001). Serum CPK level is not reported as a routine investigation for poisoned patients (Eizadi-Mood et al, 2012).

High CPK in blood may be an indication of damage to CPK-rich tissue, such as in rhabdomyolysis, myocardial infarction, myositis, myocarditis and skeletal muscle disorders including malignant hyperthermia and neuroleptic malignant syndrome (Khan, 2009). Rhabdomyolysis is a common complication among poisoning cases (Talaie et al, 2007). 
This study aimed to assess the pattern of toxic coma regarding sociodemographic, and intoxication data, causative agents, degree of coma, management modalities and outcome. In addition, it aimed to evaluate the predictive role of early CPK analysis and other variables on the outcome of toxic coma.

\section{Subjects and methods}

Study design: A Cross sectional prospective study.

Place of study: Poison Control Centre, Ain Shams University (PCCASU).

Inclusion criteria

Selected one hundred patients with toxic coma who were admitted to the ICU of PCCASU.

\section{Exclusion criteria}

Patients with history of any disease or condition that may alter results of CPK level, like muscle diseases such as dermatomyositis, polymyositis, muscular dystrophy, myopathy or rhabdomyolysis, chronic renal disease, epilepsy, receiving intramuscular injections, myocardial infarction, myocarditis, post arrest, trauma, malignancy, autoimmune diseases, overwhelming sepsis ,or patients presented with coma due to traumatic, pathological or metabolic causes (EizadiMood et al., 2012).

Careful history was taken from the legally authorized relatives, and then clinical examination was carried out to determine the clinical features of toxic coma. Two samples of arterial blood for blood gases analysis and venous blood for biochemical and toxicological analysis were collected from each patient on admission. Serum CPK was measured by a kinetic method using Biomed CK-NAC kit [ Sumathi et al., 2014], reference range: 24- $195 \mathrm{u} / \mathrm{l}$ for men and 24 $170 \mathrm{u} / \mathrm{l}$ for women [Hassan and Madboly, 2013].

An observation sheet was designed; it included sociodemographic data (age, sex, and residence), poisoning data (causative agents, route and mode of poisoning), delay time and duration of hospitalization, grade of coma in addition to investigational data, treatment modalities and outcome. Patients were observed till recovery, complications or death.

\section{Ethical considerations}

Full informed consent was taken from the patients guardians for participating in the study. Ethical committee ASU and PCCASU manger approvals were obtained.

\section{Statistical analysis}

Data were analyzed using statistical package for social science (SPSS) version 18. Quatitative data were presented as mean and standard deviation (SD). Qualitative data were presented as frequency and percentage. Quantitative variables were compared using the independent samples unpaired student (t) test. Qualitative variables were compared using the Chisquared $\left(\mathrm{x}^{2}\right)$ test. Area under the receiver operating characteristic (ROC) curve of CPK in prediction of outcome was measured with $95 \%$ confidence interval (CI). For interpretation of results, $\mathrm{P}<0.05$ was considered significant.

\section{Results}

Among the 100 intoxicated comatose patients, there was male predominance (56\%). The majority of patients (64\%) were in the 18 - 40 years age group. Most of patients originated from Giza (50\%) and Cairo (40\%) governorates. Toxicity was mostly domestic in $85 \%$ of cases. Oral route was the commonest (89\%), the mode of intoxication was mainly suicidal (51\%) followed by overdose route in $27 \%$ (Table 1).

The most frequent toxic agent inducing coma, in this study, was organophosphates (OP) accounting for $20 \%$ of cases, followed by carbamazepine (19\%) and tramadol (16\%) (Table 1, figure 1). Most of patients presented between 2-6 hours (76\%) while 14\% had a time delay more than 6 hours. Only $10 \%$ of patients arrived hospital in less than 2 hours after toxic agent consumption. The mean duration of hospitalization was $3.35 \pm 2.61$ (1-20) days.

Regarding the level of consciousness; it was found that most of cases presented with GCS $\leq 8$ (56\%), followed by GCS between 9 -12 (37\%). According to Reed's classification of coma, grade II coma was the commonest grade ( $62 \%$ ) followed by grade III in $19 \%$ of cases and grade IV in $16 \%$ of cases ( Table 2).

In the current study, specific toxicological screening was not required for almost one third of cases (30\%) where diagnosis based on either history of exposure or typical clinical picture. Other toxicological tests included a drug of abuse urine screen (for $30 \%$ of cases), plasma pseudocholinesterase level (20\% of cases), carboxyhemoglobin COHb level (8\%), plasma carbamazepine level (7\%), alcohol level (4\%), and lithium level (1\%).

Regarding treatment measures in this study, all patients received $\mathrm{O}_{2}$ supplementation, and 34\% of cases needed airway support in the form of endotracheal intubation. In 14\%, gastric lavage was performed, while activated charcoal was given to $6 \%$ of intoxicated patients. Decontamination was not indicated in most patients (80\%) and antidotes administration was not given in more than half of cases (58\%). The commonest used antidotes were atropine and oximes in $19 \%$ followed by naloxone in $12 \%$ of cases. Multiple Doses Activated Charcoal (MDAC) were given in $8 \%$ of cases and only one case underwent hemodialysis. Regarding supportive measures, IV fluids were given to all patients, while $27 \%$ of cases required mechanical ventilation. Sodium bicarbonate $\left(\mathrm{NaHCO}_{3}\right)$ and dopamine were given to $12 \%, 8 \%$ of cases respectively

There was significant association between mortality and patient age, duration of hospital stay, admission CPK and Reed's coma grade; while there was no significant relation between mortality and time delay, GCS, causative agent, or mode of poisoning (Table 3, 4).

Lower $\mathrm{PH}$ and higher $\mathrm{PaCO}_{2}$ values were significantly correlated with mortality. On the other hand, $\mathrm{HCO}_{3}, \mathrm{O}_{2}$ saturation, random blood glucose, urea and creatinine showed no significant difference between survivors and non-survivors (Table 5). 
The mean CPK level on admission was

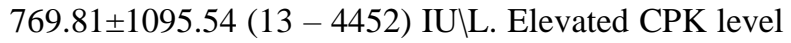
on admission had a significant correlation with death. The area under the ROC curve of CPK on admission for prediction of mortality was 0.92 and the cutoff level of 1265 achieved $92 \%$ sensitivity with $87 \%$ specificity to predict the mortality in the current study (Figure 2).

Regarding treatment modalities, there was significant relation between the need for intubation or mechanical ventilation and mortality. In addition, there was significant association between administration of antidotes and outcome as in the current study most of non-survivors did not receive antidotes. However, there was no significant association between decontamination, enhanced elimination and other supportive measures with the mortality (Table 6).

Table (1): Distribution of demographic variables (age, sex and residence) and intoxication data (Place, route, mode of poisoning and toxic agent) of the studied patients.

\begin{tabular}{|c|c|c|c|}
\hline & Variable & Number & Percent (\%) \\
\hline \multirow[t]{5}{*}{ Age (year) } & $<18$ & 14 & $(14 \%)$ \\
\hline & $18-40$ & 64 & $(64 \%)$ \\
\hline & $40-60$ & 20 & $(20 \%)$ \\
\hline & $>60$ & 2 & $(2 \%)$ \\
\hline & $>60$ & 2 & $(2 \%)$ \\
\hline \multirow[t]{2}{*}{ Sex } & Male & 56 & $(56 \%)$ \\
\hline & Female & 44 & $(44 \%)$ \\
\hline \multirow[t]{3}{*}{ Residence } & Cairo & 40 & $(40 \%)$ \\
\hline & Giza & 50 & $(50 \%)$ \\
\hline & Others & 10 & $(10 \%)$ \\
\hline \multirow[t]{2}{*}{ Place of toxicity } & Home & 85 & (85\%) \\
\hline & Others & 15 & $(15 \%)$ \\
\hline \multirow[t]{3}{*}{ Route } & Oral & 89 & $(89 \%)$ \\
\hline & Inhalation & 8 & $(8 \%)$ \\
\hline & Injection & 3 & $(3 \%)$ \\
\hline \multirow[t]{3}{*}{ Mode } & Suicidal & 51 & $(51 \%)$ \\
\hline & Overdose & 27 & $(27 \%)$ \\
\hline & Accidental & 22 & $(22 \%)$ \\
\hline \multirow[t]{11}{*}{ Toxic agents } & OP & 20 & $(20 \%)$ \\
\hline & Carbamazepine & 19 & (19\%) \\
\hline & Tramadol & 16 & $(16 \%)$ \\
\hline & $\mathrm{CO}$ & 8 & $(8 \%)$ \\
\hline & Antipsychotic & 8 & $(8 \%)$ \\
\hline & Unknown & 7 & $(7 \%)$ \\
\hline & TCA & 7 & $(7 \%)$ \\
\hline & Mixed overdose & 6 & $(6 \%)$ \\
\hline & Opiate & 4 & $(4 \%)$ \\
\hline & Methanol & 4 & $(4 \%)$ \\
\hline & Lithium & 1 & $(1 \%)$ \\
\hline
\end{tabular}

Table (2): Distribution of coma scale determined by (Glasgow coma Scale and Reed's Coma Scale) of the studied patients.

\begin{tabular}{|l|c|c|}
\hline \multirow{3}{*}{ GCS } & & No (\%) \\
\cline { 2 - 3 } & $\leq 8$ & $56(56 \%)$ \\
\cline { 2 - 3 } & $9-12$ & $37(37 \%)$ \\
\hline \multirow{3}{*}{ Reed's Coma Scale } & $>12$ & $7(7 \%)$ \\
\cline { 2 - 3 } & Coma-grade I & $1(1 \%)$ \\
\cline { 2 - 3 } & Coma grade II & $64(64 \%)$ \\
\cline { 2 - 3 } & Coma grade III & $19(21 \%)$ \\
\cline { 2 - 3 } & Coma grade IV & $16(16 \%)$ \\
\hline
\end{tabular}


Table (3): Independent t-test showing relation between different variables (Age, delay time, hospital stay, GCS and admission CPK) and the mortality in the studied patients.

\begin{tabular}{|l|c|c|c|c|}
\hline Variables & $\begin{array}{c}\text { Survivors (88 patients) } \\
\text { Mean } \pm \text { SD }\end{array}$ & $\begin{array}{c}\text { Non-survivors (12 patients) } \\
\text { Mean } \pm \text { SD }\end{array}$ & $\begin{array}{c}\text { Independent sample } \\
\text { t-test }\end{array}$ & P -value \\
\hline Age & $29.84 \pm 14.02$ & $41.50 \pm 16.42$ & 2.64 & $0.009^{*}$ \\
\hline $\begin{array}{l}\text { Delay } \\
\text { time(hours) }\end{array}$ & $3.5 \pm 4.4$ & $4.75 \pm 2.34$ & 0.96 & 0.34 \\
\hline $\begin{array}{l}\text { Hospital stay } \\
\text { (days) }\end{array}$ & $2.89 \pm 1.85$ & $6.66 \pm 4.53$ & 5.28 & $<0.001^{*}$ \\
\hline GCS & $9.59 \pm 2.23$ & $8.33 \pm 0.98$ & 1.91 & 0.06 \\
\hline Admission CPK & $552.07 \pm 860.88$ & $2366.50 \pm 1334.07$ & 6.36 & $<0.001^{*}$ \\
\hline
\end{tabular}

SD: Standard Deviation- $P>0.05$ : Non significant $-P<0.05 *$ : Significant

Table (4): Chi-square statistical analysis showing the relation between different variables (Toxic agent, mode of poisoning, and Reed coma scale) and mortality in the studied patients.

\begin{tabular}{|c|c|c|c|c|}
\hline Variables & & Survivors N (\%) & Non-survivors N (\%) & $\mathrm{P}$-value \\
\hline \multirow{11}{*}{ Toxic agent } & OP & $16(18.2 \%)$ & $4(33.3 \%)$ & \multirow{11}{*}{0.11} \\
\hline & Carbamazepine & $16(18.2 \%)$ & $3(25.0 \%)$ & \\
\hline & Tramadol & $15(17 \%)$ & $1(8.3 \%)$ & \\
\hline & $\mathrm{CO}$ & $6(6.8) \%)$ & $2(16.7 \%)$ & \\
\hline & Antipsychotic & $8(9.1 \%)$ & $0(0 \%)$ & \\
\hline & Unknown & $7(8 \%)$ & $0(0 \%)$ & \\
\hline & TCA & $7(8 . \%)$ & $0(0.0 \%)$ & \\
\hline & Mixed & $6(6.8 \%)$ & $0(0 \%)$ & \\
\hline & Methanol & $4(4.5 \%)$ & $0(0.0 \%)$ & \\
\hline & Opiate & $3(3.4 \%)$ & $1(8.3 \%)$ & \\
\hline & Lithium & $0(0 \%)$ & $1(8.3 \%)$ & \\
\hline \multirow{3}{*}{ Mode of poisoning } & Suicidal & $45(51.1 \%)$ & $6(50 \%)$ & \multirow{3}{*}{0.96} \\
\hline & Accidental & $19(21.6 \%)$ & $3(25 \%)$ & \\
\hline & Overdose & $24(27.3 \%)$ & $3(25 \%)$ & \\
\hline \multirow[t]{4}{*}{ Reed's coma scale } & Grade I & $1(1.1 \%)$ & $0(0.0 \%)$ & \multirow{4}{*}{$0.009 *$} \\
\hline & Grade II & $60(68.2 \%)$ & $2(16.7 \%)$ & \\
\hline & Grade III & $16(18.2 \%)$ & $3(25 \%)$ & \\
\hline & Grade IV & $10(10.22 \%)$ & $8(66.7 \%)$ & \\
\hline
\end{tabular}

$P>0.05$ : Non significant $-P<0.05^{*}$ : Significant

Table (5): Chi-square statistical analysis showing the relation between admission laboratory investigations and mortality in the studied patients.

\begin{tabular}{|c|c|c|c|c|c|}
\hline & & & Survivors & Non survivors & P-value \\
\hline \multirow{11}{*}{$\mathrm{ABG}$} & \multirow{3}{*}{$\mathrm{pH}$} & Normal & $67(76.1 \%)$ & $1(8.3 \%)$ & \multirow{3}{*}{$<0.05^{*}$} \\
\hline & & Respiratory acidosis & $15(17.2 \%)$ & $9(75 . \%)$ & \\
\hline & & Metabolic acidosis & $6(6.8 \%)$ & $2(16.7 \%)$ & \\
\hline & \multirow{3}{*}{$\mathrm{PaCO}_{2}$} & Normal & $67(76.1 \%)$ & $3(25 \%)$ & \multirow{3}{*}{$<0.05^{*}$} \\
\hline & & Increased & $15(17 \%)$ & $9(75 \%)$ & \\
\hline & & Decreased & $6(6.8 \%)$ & $0(0 \%)$ & \\
\hline & \multirow{3}{*}{$\mathrm{HCO}_{3}$} & Normal & 75( 85.2) & $9(75 \%)$ & \multirow{3}{*}{$>0.05$} \\
\hline & & Increased & $7(7.9 \%)$ & $2(16.7 \%)$ & \\
\hline & & Decreased & $6(6.8 \%)$ & $2(16.7 \%)$ & \\
\hline & \multirow{2}{*}{$\mathrm{O}_{2}$ saturation } & Normal & $68(77.2 \%)$ & $7(58.3 \%)$ & \multirow[t]{2}{*}{$>0.05$} \\
\hline & & Decreased & $20(22.7 \%)$ & $5(41.6 \%)$ & \\
\hline \multirow{3}{*}{\multicolumn{2}{|c|}{ Random blood sugar }} & Normal & $74(84.1 \%$ & $1(8.3 \%)$ & \multirow{3}{*}{$>0.05$} \\
\hline & & Hypoglycemia & $7(8.0 \%)$ & $0(0 \%)$ & \\
\hline & & Hyperglycemia & $7(8.0 \%)$ & $1(8.3 \%)$ & \\
\hline \multirow{2}{*}{\multicolumn{2}{|c|}{ Urea }} & Normal & $84(95.5 \%)$ & $1(8.3 \%)$ & \multirow{4}{*}{$>0.05$} \\
\hline & & Increased & $4(4.5 \%)$ & $1(8.3 \%)$ & \\
\hline \multirow{2}{*}{\multicolumn{2}{|c|}{ Creatinine }} & Normal & $84(95.5 \%)$ & $1(8.3 \%)$ & \\
\hline & & Increased & $4(4.5 \%)$ & $1(8.3 \%)$ & \\
\hline
\end{tabular}

$P>0.05$ : non-significant, $P<0.05^{*}$ : significant 
Table (6): Chi-square statistical analysis showing the relation between treatment modalities and the mortality in the studied patients.

\begin{tabular}{|c|c|c|c|c|}
\hline & & $\begin{array}{l}\text { Survivors } \\
\text { N (\%) }\end{array}$ & $\begin{array}{c}\text { Non survivors } \\
\text { N (\%) }\end{array}$ & P-value \\
\hline \multirow[t]{2}{*}{ Emergency measures } & Oxygen & $88(100 \%)$ & 12(100\%) & \multirow{2}{*}{$<0.001^{*}$} \\
\hline & Intubation & $23(26.1)$ & $11(91.7)$ & \\
\hline \multirow{3}{*}{ Decontamination } & None & $69(78.4 \%)$ & 11(91.7\%) & \multirow{3}{*}{0.51} \\
\hline & GL & $13(14.8 \%)$ & $1(8.3 \%)$ & \\
\hline & AC by ryle tube & $6(6.8 \%)$ & $0(0 \%)$ & \\
\hline \multirow{6}{*}{ Antidotes } & None & $51(58.0 \%)$ & $7(58.3 \%)$ & \multirow{6}{*}{$0.038 *$} \\
\hline & Atropine and Oximes & $15(17.0 \%)$ & 4(33.3\%) & \\
\hline & Naloxone & $12(13.6 \%)$ & $0(0 \%)$ & \\
\hline & $100 \%$ O2 & $7(7.9 \%)$ & $1(8.3 \%)$ & \\
\hline & Hyperbaric O2 & $6(6.8 \%)$ & $0(0 \%)$ & \\
\hline & Ethanol & $4(4.5 \%)$ & $0(0 \%)$ & \\
\hline \multirow{3}{*}{ Enhanced elimination } & None & $82(93 \%)$ & $9(75 \%)$ & \multirow{3}{*}{0.23} \\
\hline & MDAC & $6(6.8)$ & $2(16.3)$ & \\
\hline & Dialysis & $0(0 \%)$ & $1(8.3 \%)$ & \\
\hline \multirow{4}{*}{ Supportive treatment } & I.V fluids & $88(100 \%)$ & $12(100 \%)$ & \\
\hline & Mechanical ventilation & 17 (19.3\%) & $10(83.3 \%)$ & $<0.001 *$ \\
\hline & $\mathrm{NaHCO}_{3}$ & $10(11.3 \%)$ & $2(16.3 \%)$ & 0.42 \\
\hline & Dopamine & $3(3.4 \%)$ & $5(41.6 \%)$ & 0.34 \\
\hline
\end{tabular}

SD: Standard Déviation- $P>0.05$ : Non significant $-P<0.05 *$ : Significant

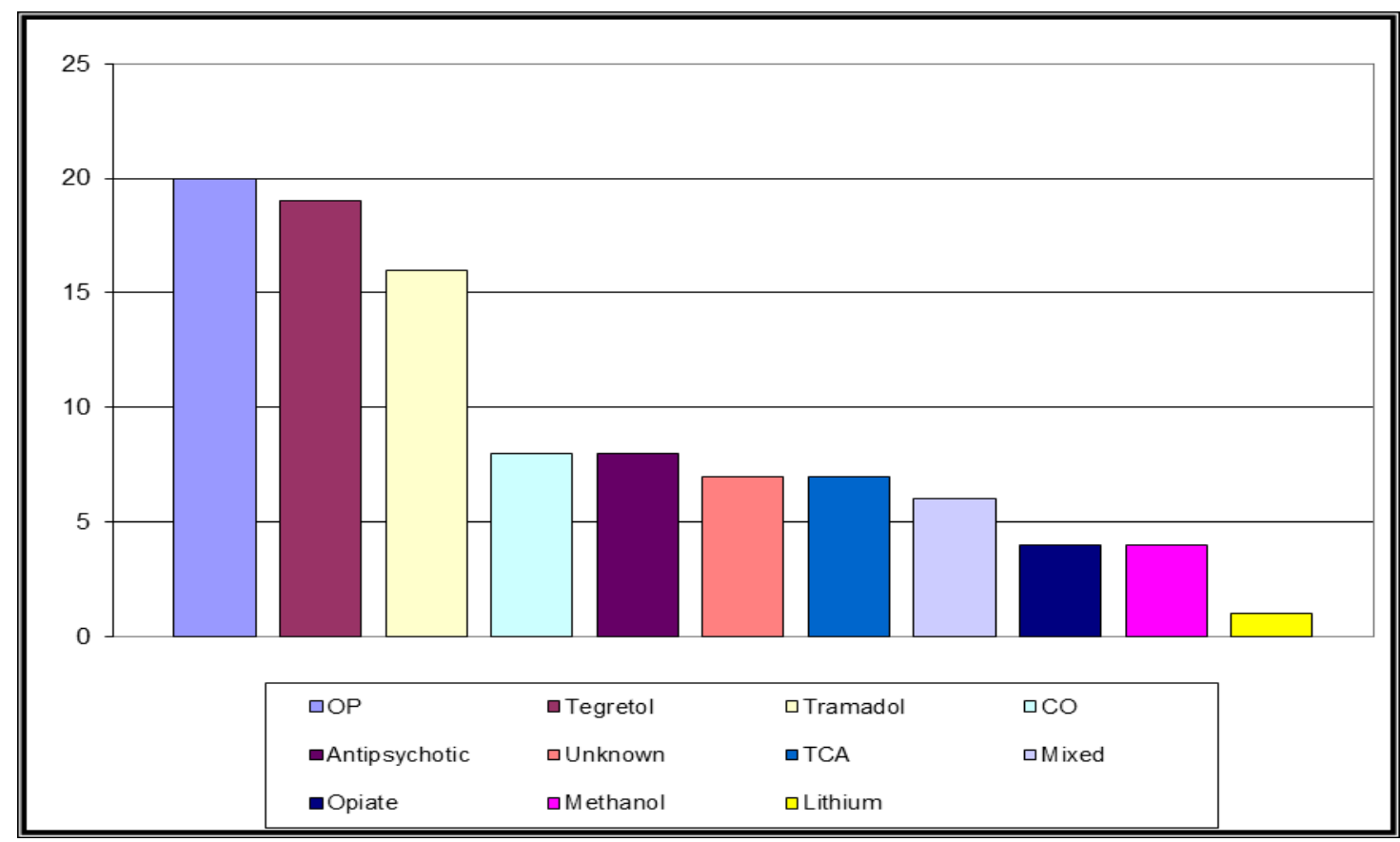

Figure (1): Bar chart showing different types of toxic agents in the studied patients. 


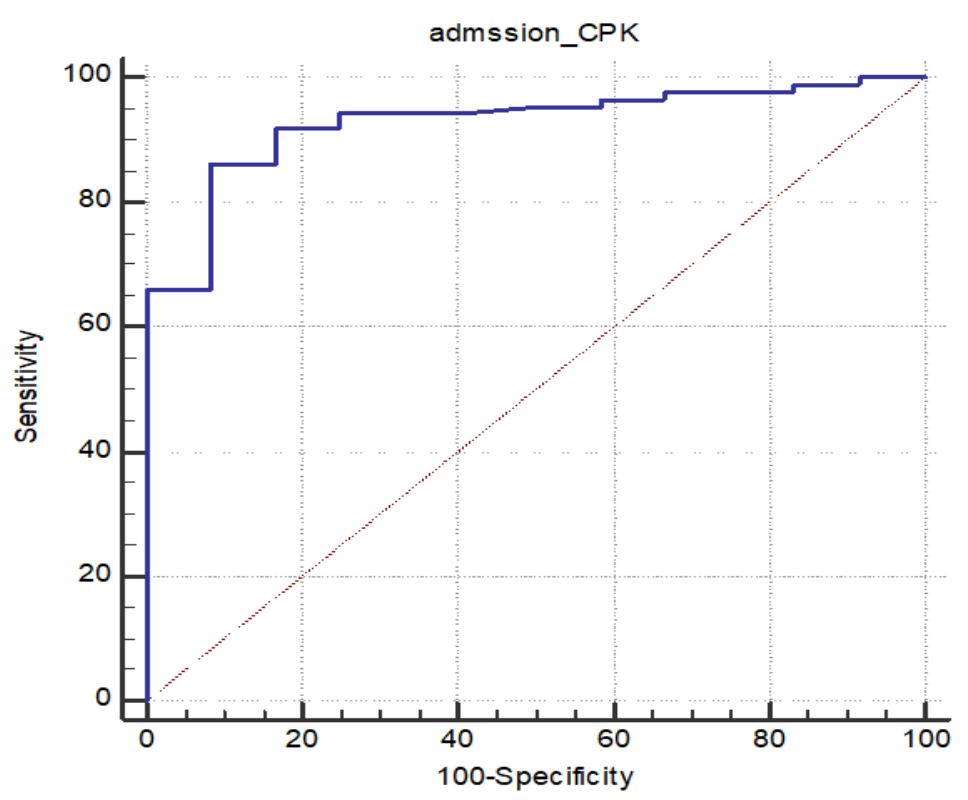

Figure (2): ROC Curve for sensitivity and specificity of CPK in prediction of outcome in the studied patients.

\section{Discussion}

In the present study the demographic characteristics were similar to other previous studies, the most affected age group was 18-40 years and cases of males outnumbered females (Sarivastave et al., 2005 Hassanian-Moghaddam et al., 2006 Eizadi-Mood et al., 2012 and Forsberg et al., 2012). Male predominance could be due to higher rate of addiction in men and exposure to occupational hazards, as compared with females.

The mode of poisoning in the current study was also similar to previous studies by Sarivastave et al., (2005), Hassanian-Moghaddam et al., (2007) and Kann et al., (2014), where the most common mode of poisoning was suicidal. Ingestion was the route of exposure in most of cases and this was in agreement with the study carried out by Moawad et al., (2015).

However, this study differs from previous studies in the coma-causing toxic agent. The commonest toxic agent inducing coma in the current study was OP followed by carbamazepine then tramadol, while opioids were the most frequent type of poisoning inducing coma in two other studies (Talaie et al., (2007) and Mousavi et al., (2015)). Dadpour et al., (2017) reported that the most frequent type of poisoning was neuropsychiatric drugs followed by alcohol. In a study in Sweden in 2012, the causes of toxic coma were ethanol alone followed by sedativehypnotics then ethanol in combination with sedativehypnotics (Forsberg et al., 2009).

These differences in toxic agents inducing coma may be attributed to cultural dissimilarities between countries together with differences in accessibility of these agents. The cheapness and easy availability of pesticides and the wide range for therapeutic use of carbamazepine may explain using them more for poisoning in this study.

The current study showed that specific toxicological screening was not performed in about one third of cases (30\%); this is attributed to establishment of diagnosis by history and clinical examination. Urine screen for drug abuse was done in only $30 \%$ of cases. The clinical value of toxicological screen has been inquired as previous studies revealed that they rarely influence the therapy, moreover in most cases, supportive treatment alone is sufficient without the need for specific drug identification (Buylaert 2000 and Montague et al., 2001). However, specific drug analysis and quantitative determination will guide therapy in a few cases as identifying that the coma is due to lithium or methanol, will point to the necessity of specific therapy like hemodialysis (Osterloh and Snyder, 1998).

In the current study, most of patients recovered and were discharged. Pneumonia was the most common complication (17\%) whereas the least was acute renal failure (3\%). The same was found by Christ et al., (2006) who reported that $17 \%$ of overdose patients admitted to the ICU developed pneumonia, also Eizadi-Mood et al., (2012) found that the least frequent complication in a study on poisoned comatose patients was acute renal failure (3.75\%).

In this study mortality rate was $12 \%$. Moawad et al., (2015), as well as Panda et al., (2015) reported similar results with a mortality rate of comatose intoxicated patients of $14.2 \%$ and $15 \%$ respectively. However, a study done by Forsberg et al., (2009) among impaired consciousness patients in the emergency room revealed that hospital mortality rate was $2.8 \%$ in coma due to poisoning. This favorable outcome could be attributed to the fact that coma induced by intoxication is usually treatable.

There was significant relation between patient age and length of hospital stay with the mortality. This was in accordance with Eizadi-Mood et al., (2011) who reported that increasing age was associated with fatal outcome in drug-induced coma, while Bates, (2001) 
concluded that, the longer a patient remains in a coma the poorer the outcome.

In the present study, there was significant association between the Reed's coma grade and the mortality where highest mortality rate was found among those with grade IV (66.7\%). This result was in agreement with Hassanian-Moghaddam et al., (2007) who reported that mortality was higher in grade III and IV, $11 \%$ and 34\% respectively. Also Chadha, (2003) reported that patients in grade III require intubation and placement in an intensive care unit while patients in grade IV need advanced interventions to sustain life since mortality was higher in these coma grades.

The current study revealed that there was no significant association between the GCS and mortality. This result was in accordance with Kheirabadi et al., (2015), also Duncan and Thakore, (2009) who suggested that it could be safe to observe poisoned patients with decreased consciousness, even if they have a GCS of 8 or less, in the emergency department. However, Eizadi-Mood et al., (2011) found that GCS has a useful role in outcome prediction of patients with drug overdose.

Blood gases data in the current study revealed that acidosis and respiratory failure were significantly associated with mortality, Hua et al., (2017) found the same result and reported that mortality was associated with lower mean $\mathrm{pH}$ and higher mean $\mathrm{PaCO} 2$.

Based on results of the current study, high admission serum CPK level achieved 92\% sensitivity and $87 \%$ specificity to predict mortality. Eizadi-Mood et al., (2012) in a prospective study concluded that serum CPK level at admission might give clue of poisoned patients' outcome and that with higher levels of CPK the risk of complications and death increased. In another retrospective study on poisoned patients, a significant correlation between serum CPK level and death was also found (Mousavi et al., 2015). Shadnia et al., 2015 showed significant correlation of serum CPK level and outcome in valproate intoxication. In contrast, Dadpour et al., (2017) found no significant relation between serum CPK level in the first 24 hours and mortality of intoxicated patients.

Acidosis itself may lead to moderate elevations in serum CPK level, with positive correlation with the degree of acidosis (Karki et al, 2004). The commonest toxic agent-inducing coma in the current study was OP, Hassan and Madboly, (2013) reported that excess acetylcholine seen in OP poisoning result in reversible myocyte injury and increase of different muscle enzymes, including CPK.

Regarding treatment measures in this study, there was significant relation between the need for intubation or mechanical ventilation and mortality. This was in agreement with a study by Jayashree and Singhi, (2011) who found mechanical ventilation needed in $75 \%$ of non-survivors and explained that as the need for mechanical ventilation itself is a poor prognostic factor, which point to severe toxicity and accompanied with prolonged duration of hospitalization.

In addition, administration of antidotes had significant association with favorable outcome. Betten et al., (2006) concluded that the proper use of antidotes in the ICU when combined with appropriate supportive care reduce the morbidity and mortality

However, there was no significant association between decontamination, enhanced elimination and other supportive measures with the mortality. Zilker, (2014) mentioned that no evidences confirmed the influence of elimination from the gastrointestinal tract as emesis, or gastric lavage. Paepe et al., (2012) concluded that the results of outcome of gut decontaminations studies in overdose patients are weighted against a lack of beneficial effect.

\section{Conclusion}

Based on the findings of the current study, older age, longer duration of hospitalization and higher grade of Reed's classification of coma predispose the patients to poor outcome. Respiratory acidosis, respiratory failure and elevated CPK on admission are other factors that can predict mortality in intoxicated comatose patients. In addition, this study concluded that requirements for intubation and mechanical ventilation indicated poorer outcome, while administration of antidotes was correlated with better outcome.

\section{Recommendations}

The current study encourage the physician to consider age , duration of coma ,Reed's classification of coma and respiratory acidosis in addition to elevated admission CPK level and the need for intubation and mechanical ventilation as useful tools to identify prognosis early in comatose intoxicated patients. Multi-centre studies are needed involving larger sample size, to verify the findings in the present study and to evaluate the usefulness of these prognostic indices toward adverse outcome.

\section{References}

Bates D (2001): The prognosis of medical coma. Journal of Neurology, Neurosurgery, and Psychiatry, $71: 20$ 23.doi:10.1136/jnnp.71.suppl_1.i20

Betten D, Vohra R, Cook M, et al (2006): Antidote use in the critically ill poisoned patient. Journal of Intensive Care Medicine, 21: 255-277. doi: 10.1177/0885066606290386

Buylaert WA (2000): Coma induced by intoxication. Acta Neurol Belg; 100(4):221-224.

Chadha I (2003): Poisoning. Indian Journal of anesthesia, 47: 402-411.

Christ A, Arranto C and Schindler C (2006): Incidence, risk factors, and outcome of aspiration pneumonitis in ICU overdose patients. Intensive Care Medicine, 32: 1423-1427. doi: 10.1007/s00134-006-0277-4

Dadpour B, Tajoddini Sh, Shaarbaf Eidgahi E, et al (2017): Role of serum creatinine phosphokinase in outcome prediction of intoxicated patients; a Brief Report. Emergency, 5(1): 1-4.

David M \& Greer MD (2013): Clinical evaluation of coma and brain death. Neurocritical Care Society Practice Update, 30: 359-364.

Duncan R and Thakore S (2009): Decreased Glasgow Coma Scale score does not mandate 
endotracheal intubation in the emergency department. Journal of Emergency Medicine,37(4):451-455. doi: 10.1016/j.jemermed.2008.11.026

Eizadi-Mood N, Sabzghabaee A, Gheshlaghi F, et al (2012). Admission creatine phosphokinase in acute poisoning: Is it a predictive factor for the treatment outcome?. The Journal of the Pakistan Medical Association, 62: 67-70.

Eizadi-Mood N, Sabzghabaee A and Dehkordi K (2011): Applicability of different scoring systems in outcome prediction of patients with mixed drug poisoning-induced coma. Indian Journal of Anesthesia, 55:599-604. doi: 10.4103/0019-5049.90616

Forsberg S, Höjer J, Enander C et al (2009): Coma and impaired consciousness in the emergency room: characteristics of poisoning versus other causes. Emergency Medicine Journal, 26:100102. doi: 10.1136/emj.2007.054536

Forsberg S, Höjer J, and Ludwigs U (2012): Hospital mortality among poisoned patients presenting unconscious. Clinical Toxicology, 50:254257. doi: 10.3109/15563650.2012.670245

Hassan NA and Madboly AG, (2013): Correlation between Serum Creatine Phosphokinase and Severity of Acute Organophosphorus Poisoning: A Prospective Clinical Study (2012-2013). Journal Of Environmental Science 4(5):18-29.

Hassanian-Moghaddam H , Baghbanian N, and Kolahi A (2007):Evaluating the factors accompanying coma in patients who admitted in poisoning ICU in Loghman Hakim Hospital. Iranian Journal of Toxicology, 1(2): 56-63.

Hassanian-Moghaddam H , Kolahi A, and Yaghooti N (2006):Evaluation causes of coma in patients who admitted in poisoning ICU in Loghman Hakim Hospital. Science Journal Forensic Medcine of Iran, 12: 90-94.

Heyerdahl F1, Bjornas MA, Hovda KE, et al (2008): Acute poisonings treated in hospitals in Oslo: A one-year prospective study (II): clinical outcome. Clinical Toxicology, 46: 42-49.doi: 10.1080/15563650701210048

Hua A, Haight S, Hoffman RS et al (2017): Endotracheal Intubation after Acute Drug Overdoses: Incidence, Complications, and Risk Factors. Journal of Emergency Medicine, 52:59-65.

doi: 10.1016/j.jemermed.2016.07.114

Karki P, Ansari J A, Bhandary S, et al, (2004): Cardiac and electrocardiographical manifestations of acute organophosphate poisoning.Singapore Med. J., 45: 385-389

Kann L, Kinchen S, Shanklin SL, et al (2014): Youth risk behavior surveillance--United States, 2013.MMWR Suppl., 63 (4):1-168.

Khan FY (2009): Rhabdomyolysis: A review of the literature. Netherlands The Journal of Medicine, 67:272-283.

Kheirabadi AR, Tabeshpour J, and Afshari R (2015): Comparison of three consciousness assessment scales in poisoned patients and recommendation of a new scale: AVPU Plus. Asia Pacific Journal of Medical Toxicology, 4:58-63. doi: 10.22038/APJMT.2015.5080

Moawad AM, Abd El-salam MH, Ali AA et al (2015): Toxic Coma Incidence At Kasr-Alainy National Poison Center [master's thesis].Cairo University, P (63-95) unpublished.

Montague RE, Grace RF, Lewis JH et al (2001): Urine drug screens in overdose patients do not contribute to immediate clinical management. Therapeutic Drug Monitoring, 23: 47-50.

Mousavi SR, Vahabzadeh M, Mahdizadeh A et al (2015): Rhabdomyolysis in 114 patients with acute poisonings. Journal of research in medical sciences, 20:239-243.

Osterloh JD, Snyder JW (1998): Laboratory principles and techniques to evaluate the poisoned or overdosed patient. In: Goldfrank's Toxicologic Emergencies. Connecticut, Appleton \& Lange, pp. 63-75.

Paepe P De, Lemoyne S and Buylaert W (2012): Disorders of Consciousness Induced by Intoxication. Neurologic Clinics, 30:359-384. doi:10.1016/j.ncl.2011.10.003

Panda BB, Hansda MK, Mishra K et al (2015): Study of Poisoning Cases in an Indian Tertiary Care Teaching Hospital. Journal of Indian Academic Forensic Medicine, 37:165-168. doi: 10.5958/0974-0848.2015.00040.8

Sarivastave A, Peshin SS, Kaleekal T et al (2005): An epidemiological study of poisoning cases reported to the National Poisons Information Centre, All India Institute of Medical Sciences, New Delhi. Human and Experimental Toxicology, 24:279 - 285. doi:10.1191/0960327105ht527oa

Shadnia S, Amiri H, Hassanian-Moghaddam $\mathrm{H}$ et al (2015): Favorable results after conservative management of 316 valproate intoxicated patients. Journal of research in medical sciences, 20:656-661. doi: 10.4103/17351995.166211

Sumathi M, Kumar S, Shashidhar K et al (2014): Prognostic significance of various biochemical parameters in acute organophosphorus poisoning, Toxicol Int; 21(2): 167-71.

Talaie H, Pajouhmand A, Abdollahi M, et al (2007): Rhabdomyolysis among acute human poisoning cases. Human \& experimental toxicology, 26: 557-561. doi: 10.1177/0960327107078667

Young GB (2009): Coma, Annals of the New York Academy of Sciences, 1157: 32-47. doi: 10.1111/j.1749-6632.2009.04471.x 


\section{الملخص العربي}

الغيبوبة الناتجة عن التسمم الحاد: خصائصها ودور القياس المبكر للكرياتين فوسفوكيناز للتنبؤ بمخرجاتما

$$
\text { ايمان عبد الفتاح محمد خليفها والسيد حمدي السيد جاويش }
$$

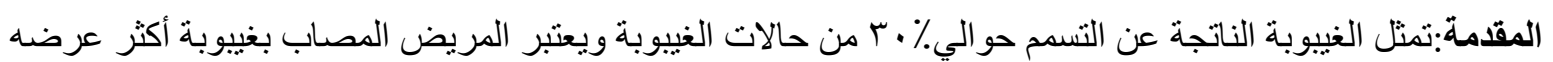

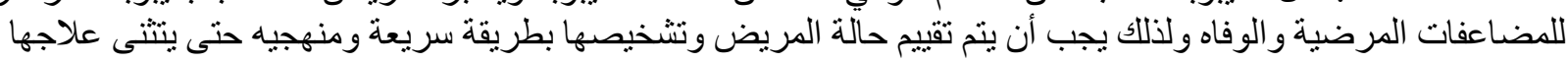

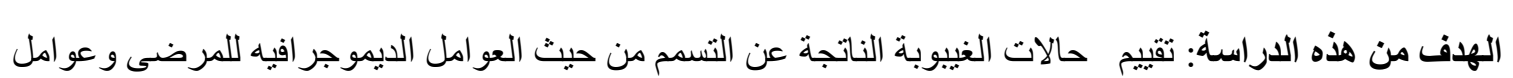

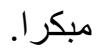

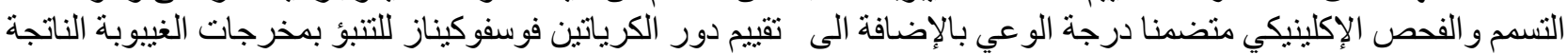

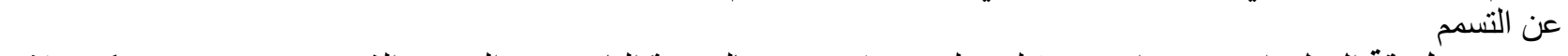
طريقة العمل: اجريت در اسه مستقبليه على . ․ 1 مريض بالغيبوبة الناتجه عن التسمم والذين تم حجز هم في مركز علاج

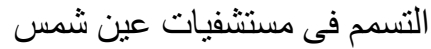

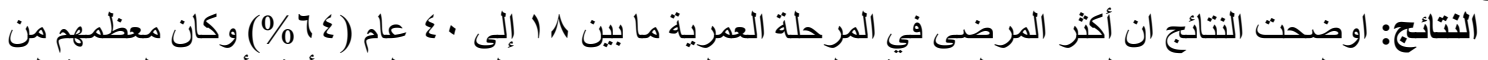

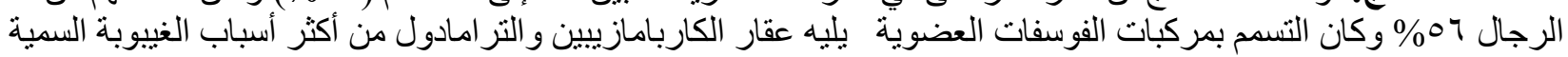

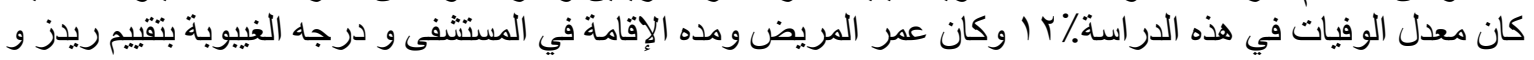

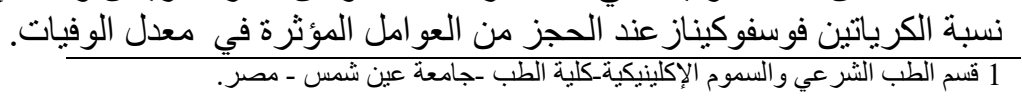
2 قسم الطب الثر عي والسموم الإلكلينكية-كلية الطب -جامعة الأزهر - مصر. 